\title{
Suppression of play fighting by amphetamine does not depend upon peripheral catecholaminergic influences
}

\author{
WILLIAM W. BEATTY, SHARON L. BERRY, and KEVIN B. COSTELLO \\ North Dakota State University, Fargo, North Dakota
}

\begin{abstract}
As reported earlier, d-amphetamine (0.25-1.0 $\mathrm{mg} / \mathrm{kg}$ ) produced a dose-dependent depression of play fighting as indexed by the frequency of pins and the total duration of play fighting. Amphetamine reduced both the frequency of play bouts and the duration of those bouts that occurred. At the highest dose, play fighting was virtually eliminated. In contrast, 4-OH-amphetamine, which crosses the blood-brain barrier less readily than does d-amphetamine, did not depress play fighting at doses from 0.25 to $2 \mathrm{mg} / \mathrm{kg}$. At $4 \mathrm{mg} / \mathrm{kg}$, this drug reduced pinning, total play duration, and the frequency of play bouts, but did not affect bout duration. In a second experiment, the effects of d-amphetamine on play fighting were studied in animals that had been adrenal demedullated, subjected to chemical sympathectomy with 6-hydroxydopamine, or given a combination of both treatments. Amphetamine produced comparable suppression of play fighting regardless of the functional state of the sympathetic nervous system. Apparently, the effects of psychomotor stimulants on play fighting by juvenile rats are mediated by the central actions of these drugs.
\end{abstract}

The psychomotor stimulants d-amphetamine and methylphenidate cause a profound and dose-dependent suppression of play fighting by juvenile rats (Beatty, Dodge, Dodge, White, \& Panksepp, 1982). Although the mechanism of this action is unknown, presumably catecholamines (CAs) are involved. In the present experiments we evaluated the possible contribution of the sympathetic branch of the autonomic nervous system to the effect of amphetamine on play. Although the psychomotor stimulants have potent effects on the central nervous system, they are powerful peripheral sympathomimetics as well, and these latter influences may have important behavioral consequences. For example, the facilitatory actions of amphetamine on memory consolidation appear to involve effects on peripheral CA systenis, especially the adrenal medulla (Martinez, Vasquez, Rigter, Messing, Jensen, Liang, \& McGaugh, 1980).

\section{EXPERIMENT 1}

In this experiment, we compared the effects of $\mathrm{d}$-amphetamine and 4-OH-amphetamine on play fighting. The latter drug has few central effects because it penetrates the blood-brain barrier with difficulty.

\section{Method}

Animals. The subjects were 18 male albino rats of a SpragueDawley-derived strain bred by the Holtzman Company, Madison, Wisconsin, and shipped to the laboratory at 21 days of age.

This research was supported by NICHD Grant HD-12620 to William W. Beatty. We thank Smith Kline Corporation for donating supplies of Dexedrine and Paredrine used in this research. Our mailing address is: Department of Psychology, North Dakota State University, Fargo, North Dakota 58105.
Except during behavioral testing, they were caged singly in standard laboratory cages in an air-conditioned animal room that was illuminated from 0700-2000 h. They had free access to food and water. Behavioral tests occurred between 1800-2000 h.

Apparatus. The test chamber, a $51 \times 32 \times 47 \mathrm{~cm}$ high box, made of plywood painted black and having a clear plastic front, was housed in a quiet room [ $45 \mathrm{~dB}(\mathrm{~A})$ re:30 microPascals at the center of the floor of the chamber]. The chamber was illuminated by two $60-\mathrm{W}$ red incandescent light bulbs mounted in desk lamps, $68 \mathrm{~cm}$ above the floor. This arrangement provided the minimum light necessary to obtain clear videotape recordings.

Procedure. At 24 days of age, test pairs $(\mathrm{N}=9)$ were formed at random, and these pairs were habituated to the apparatus for $10 \mathrm{~min}$ for 3 consecutive days. Once formed, the pairs remained intact for the duration of the study. For the following 9 days, each pair received a 10 -min-long play test $20 \mathrm{~min}$ after ip injection of d-amphetamine sulfate $(0,0.25,0.5$, or $1.0 \mathrm{mg} / \mathrm{kg}$; Dexedrine, Smith Kline) or 4-OH-amphetamine hydrobromide $(0.25,0.5,1.02 .0$, or $4.0 \mathrm{mg} / \mathrm{kg}$; Paredrine, Smith Kline). Drugs were dissolved in saline and administered at a volume of $1 \mathrm{ml} / \mathrm{kg}$. Doses are expressed as the weight of the salt. Both members of the test pair received the same treatment each test day, and the order of treatments was counterbalanced using a Latin square design.

All sessions were videotaped and scored by two raters (S.B., K.C.), who were blind to the treatment conditions. The following behaviors were scored for each pair: pinning frequency (one rat rolls the other onto its dorsal surface and stands over it), rearing frequency (either rat raises its forepaws at least $1 \mathrm{~cm}$ off the floor), and frequency, bout duration, and total duration of play fighting. Play fighting was a composite of several behaviors, including tail pulling, pouncing, boxing, wrestling, pinning, and chasing. Timing of individual play bouts continued until a clear interruption had occurred. This often resulted when a pinned animal scrambled to its feet or was released. Product-moment correlations, computed as measures of interrater reliability, were $0.94,0.92,0.83$, and 0.74 for pins, rears, play frequency, and total play duration, respectively. Data were also obtained on the frequency and duration of social investigation, but interrater reliabilities were low $(r=0.47$ and 0.45$)$, so these data are not reported. 
Data analysis. The effects of varying doses of d-amphetamine and 4-OH-amphetamine were assessed by separate analyses of variance on each measure. The saline $(0-\mathrm{mg} / \mathrm{kg})$ condition was included in each analysis.

\section{Results}

As shown in Figure 1, d-amphetamine produced the expected reduction in the frequency of pins $[\mathrm{F}(3,24)=$ $50.33, \mathrm{p}<.001]$. Subsequent analyses showed that the $0.5-$ and $1-\mathrm{mg} / \mathrm{kg}$ doses depressed pinning more than did the 0 - or $0.25-\mathrm{mg} / \mathrm{kg}$ dose $[\mathrm{Fs}(1,8)>52.75, \mathrm{p}<.001]$. The magnitude of the drug effect was greater at the 1 - than at the $0.5-\mathrm{mg} / \mathrm{kg}$ dose $[\mathrm{F}(1,8)=23.36, \mathrm{p}<.002]$. The difference between the saline and the $0.25-\mathrm{mg} / \mathrm{kg}$ condition fell just short of significance $(p=.06)$.

Treatment with 4-OH-amphetamine also affected pinning $[F(5,40)=11.17, p<.001]$, but only the

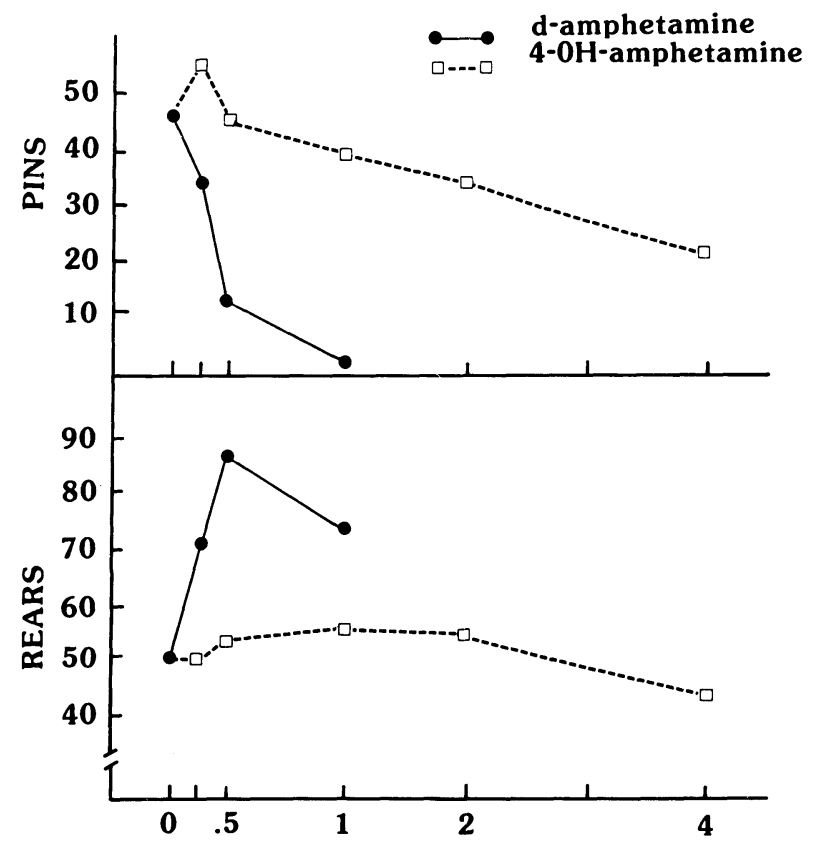

DOSE (mg/kg)

Figure 1. Mean number of pins and rears after varying doses of d-amphetamine or 4-OH-amphetamine. highest dose reduced pinning reliably compared with the saline control condition $[F(1,8)=24.94, p<.002]$.

Since pinning was highly correlated with the total duration of play fighting $(\mathrm{r}=0.94)$ and the frequency of play bouts $(r=0.92)$, the drug effects on these measures were quite similar to those described above (Table 1). Relative to the saline control, all doses of d-amphetamine depressed play on both measures $[\mathrm{Fs}(1,8)>5.73, \mathrm{p}<.05]$. Again, 4-OH-amphetamine was less potent. Relative to saline, only the highest dose reliably reduced the overall duration of play fighting $[F(1,8)=18.40, p<.001]$ and the $1-, 2-$, or $4-\mathrm{mg} / \mathrm{kg}$ doses reduced the frequency of play bouts $[\mathrm{Fs}>6.12$, $\mathrm{p}<.05]$. d-Amphetamine reduced the average duration of play bouts $[\mathrm{F}(2,16)=4.74, \mathrm{p}<.05] ; 4-\mathrm{OH}$-amphetamine had no reliable effect.

The two drugs also differed in their effects on rearing (Figure 1). Rearing was stimulated by d-amphetamine $[F(3,24)=4.49, p<.02]$, but was unaffected by 4-OH-amphetamine (see Figure 1).

\section{EXPERIMENT 2}

The differential potency of d-amphetamine and 4-OH-amphetamine is consistent with the hypothesis that the suppression of play fighting by $d$-amphetamine involves a central action of the drug. However, 4-OHamphetamine did suppress play fighting, albeit weakly, so the results of Experiment 1 are not definitive, especially since $4-\mathrm{OH}$-amphetamine does alter brain CA function, at least at high doses (Martinez, Ishikawa, Hannan, Liang, Vasquez, Jensen, Sternberg, Brewton, \& McGaugh, 1981). In Experiment 2, we examined the effects of d-amphetamine on play fighting in juvenile rats with varying degrees of damage to the sympathetic nervous system. If the effect of an amphetamine depends upon peripheral CA systems, then adrenal demedullation or chemical sympathectomy alone or in combination should attenuate the drug-induced suppression of play.

\section{Method}

Animals and Surgery. The subjects were 48 male albino rats obtained from the Holtzman Company at 21 days of age.

Table 1

Mean Play Fighting After d-Amphetamine (d-A) or 4-OH-Amphetamine (4OH) Treatment

\begin{tabular}{|c|c|c|c|c|c|c|c|c|c|c|c|c|}
\hline & \multicolumn{12}{|c|}{ Dose $(\mathrm{mg} / \mathrm{kg})$} \\
\hline & \multicolumn{2}{|c|}{0} & \multicolumn{2}{|c|}{.25} & \multicolumn{2}{|c|}{.5} & \multicolumn{2}{|c|}{1} & \multicolumn{2}{|c|}{2} & \multicolumn{2}{|c|}{4} \\
\hline & $\mathrm{d}-\mathrm{A}$ & $40 \mathrm{H}$ & $\mathrm{d}-\mathrm{A}$ & $4 \mathrm{OH}$ & $\mathrm{d}-\mathrm{A}$ & $4 \mathrm{OH}$ & $\mathrm{d}-\mathrm{A}$ & $4 \mathrm{OH}$ & $\mathrm{d}-\mathrm{A}$ & $4 \mathrm{OH}$ & $\mathrm{d}-\mathrm{A}$ & $4 \mathrm{OH}$ \\
\hline Total Play Duration & 164.6 & 164.6 & 116.9 & 191.3 & 46.5 & 170.3 & 8.1 & 148.7 & & 136.5 & & 78.9 \\
\hline Bout Frequency & 58.7 & 58.7 & 46.8 & 59.1 & 20.2 & 53.5 & 4.1 & 45.2 & & 45.8 & & 25.7 \\
\hline Bout Duration & 2.86 & 2.86 & 2.43 & 3.32 & 2.22 & 3.18 & $*$ & 3.29 & & 3.01 & & 2.78 \\
\hline
\end{tabular}

Note-Total play duration and bout duration are given in seconds.

*Not reported because only two pairs had more than three play bouts. 
At 24 days of age, 18 of the rats received bilateral adrenal demedullations (ADXM), performed under Chloropent anesthesia (Fort Dodge Laboratories, $3 \mathrm{ml} / \mathrm{kg}$ ). At the same time, 12 rats received sham operations, identical to the demedullations except that the adrenal glands were grasped with forceps but not incised. The remaining rats were untreated. All rats were caged singly and were given free access to food and water except prior to surgery. Rats in the ADXM condition were given 1\% saline solution instead of tap water to drink for 1 week following surgery, since we assumed that their adrenocortical function would be transiently impaired. Other maintenance procedures were the same as in Experiment 1, except that the animal room was illuminated from $0700-1900 \mathrm{~h}$ and the behavioral tests occurred between 0830 and $1200 \mathrm{~h}$.

Procedure. At 30 days of age, the rats were assigned randomly to pairs, with the constraint that both members of the pair had received the same surgical treatment. Once formed, the pairs remained intact for the duration of the study. The rats were adapted to the apparatus for $10 \mathrm{~min}$ per day. Following the 3rd day of adaptation, both members of each pair received $50-\mathrm{mg} / \mathrm{kg}$ ip injection of 6-hydroxydopamine $\mathrm{HBr}$ (6-OHDA, Regis Chemical, dose expressed as the weight of the salt) dissolved in physiological saline containing $0.1 \mathrm{mg} / \mathrm{ml}$ of ascorbic acid or the ascorbic-acid/saline vehicle $(1 \mathrm{ml} / \mathrm{kg})$. The pairs were assigned to conditions in such a way as to minimize differences among groups in terms of performance on the last adaptation day on the dependent variables, pins and rears. The number of pairs per treatment group was as follows: surgical control/ $6-\mathrm{OHDA}=8$, surgical control $/$ vehicle $=7 ; \mathrm{ADXM} / 6-\mathrm{OHDA}=6$, and $\mathrm{ADXM} /$ vehicle $=3$.

On the next 4 days, play fighting was studied (as described in Experiment 1) $20 \mathrm{~min}$ after an ip injection of $0,0.25,0.5$, or $1.0 \mathrm{mg} / \mathrm{kg}$ of d-amphetamine sulfate (dose expressed as the weight of the salt). Treatments were administered in a counterbalanced order (1 drug treatment/day).

\section{Results}

General observations. The ADXM rats appeared healthy but grew less rapidly postoperatively than did the controls. On the last adaptation day, their weights averaged $120.0 \mathrm{~g}$, versus $140.3 \mathrm{~g}$ for the controls ( $\mathrm{p}<.001$ ). For the 1st day after 6-OHDA treatment, the rats that received 6-OHDA gained less weight than did the vehicle-treated controls ( 4.5 vs. $8.5 \mathrm{~g}$ ), but this effect was transient. Growth over the 4 days after 6-OHDA treatment, when the behavioral data were collected, was comparable for all four groups (range of mean weight gains $=29.9$ to $34.0 \mathrm{~g}$ ).

Behavioral results. As seen in Figure 2, d-amphetamine produced comparable suppression of pinning and stimulation of rearing in all four groups. Analysis of variance of the pinning variable revealed only a main effect of amphetamine dose $[F(3,60)=42.59, p<.001]$. No other main effects or interactions approached significance $(F s \leqslant 1.48)$. Analysis of the rearing data disclosed a similar pattern. Overall, the main effect of drug dose was reliable $[F(3,60)=12.60, p<.001]$, but no other main effects or interactions were statistically significant $(\mathrm{Fs} \leqslant 2.61)$.

Because the number of pairs was small in some conditions, separate analyses of the amphetamine effect were conducted for each treatment group. Amphetamine significantly depressed pinning in each group ( $F s \geqslant$

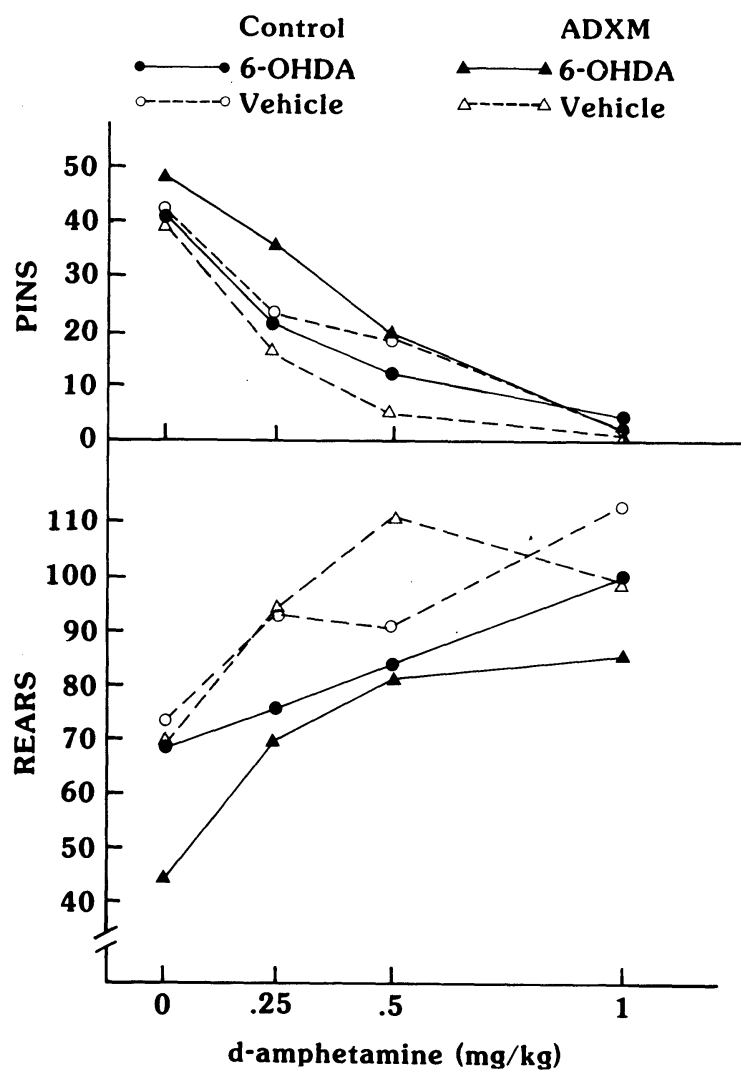

Figure 2. Mean number of pins and rears after varying doses of d-amphetamine in groups of rats that sustained adrenal demedullation (ADXM) or control operations and were injected with $50 \mathrm{mg} / \mathrm{kg}$ of 6-OHDA or vehicle $24 \mathrm{~h}$ before the first test.

$6.64, p \leqslant .03)$ and stimulated rearing $(p \leqslant .05)$ in every group except the surgical-control/vehicle group, in which the effect approached significance $(p<.08)$.

\section{DISCUSSION}

The present findings suggest that stimulation of the sympathetic nervous system contributes little, if anything, to the suppression of play fighting by moderate doses of d-amphetamine. The observation that $4-\mathrm{OH}$-amphetamine was at least eight times less potent than d-amphetamine supports this conclusion, as does the finding that neither adrenal demedullation nor peripheral treatment with 6-OHDA or the combination of these treatments attenuated the effectiveness of amphetamine in suppressing play.

Interpretation of the effects of 4-OH-amphetamine is complicated by the recent finding (Martinez et al., 1981) that $8.2-\mathrm{mg} / \mathrm{kg}$ doses of the drug cause modest, but statistically significant, reduction of dopamine and norepinephrine levels in several brain areas. However, these changes did not develop until more than $30 \mathrm{~min}$ after ip injection. Since our behavioral tests ended $30 \mathrm{~min}$ after drug treatment, it is not clear whether or not the mild suppression of play that we observed after the $4-\mathrm{mg} / \mathrm{kg}$ dose of $4-\mathrm{OH}$-amphetamine reflects a weak central action of the drug or a peripheral influence.

The finding that d-amphetamine was equally effective in animals that sustained varying degrees of damage to the sympathetic nervous system implies that the effects of d-amphetamine, 
and perhaps of 4-OH-amphetamine as well, on play are largely mediated by central actions of the drugs. In the absence of biochemical confirmation of the effectiveness of the demedullations and 6-OHDA treatments, this conclusion must be somewhat tempered. However, inspection of the adrenal glands at autopsy suggested that the adrenal medulla was completely removed in all cases. And many previous data suggest that, with the dose and route of administration of 6-OHDA used in the present study, norepinephrine levels in sympathetic nerves should have been reduced by $60 \%-80 \%$ (Kostrzewa \& Jacobowitz, 1974).

\section{REFERENCES}

Beatty, W. W., Dodge, A. M., Dodge, L. J., White, K., \& Pankse PP, J. Psychomotor stimulants, social deprivation and play in juvenile rats. Pharmacology, Biochemistry and Behavior, 1982, 16, 417-422.

Kostrzewa, R. M., \& JAcobowitz, D. M. Pharmacological actions of 6-hydroxydopamine. Pharmacological Reviews, 1974, 26, 199-288.

Martinez, J. L., Jr., Ishikawa, K., Hannan, T. J., Liang, K. C., Vasquez, B. J., Jensen, R. A., Sternberg, D., Brewton, C., \& McGaugh, J. L. Actions of 4-OH amphetamine on active avoidance conditioning and regional brain concentrations of norepinephrine and dopamine. Society for Neuroscience Abstracts, 1981, 7, 523.

Martinez, J. L., Jr., Vasquez, B. J., Rigter, H., Messing, R. B., Jensen, R. A., Liang, K. C., McGaugh, J. L. Attenuation of amphetamine-induced enhancement of learning by adrenal demedullation. Brain Research, 1980, 195, 433-443.

(Manuscript received for publication May 12, 1983.) 